\title{
Investigation of the dynamic characteristics of the "building - pile foundation" system with the random parameters of foundation soils
}

\author{
Valeriya Pshenichkina, Artyom Zhidenko*, Kseniya Suhina, and Vyacheslav Drozdov \\ Volgograd State Technical University, 400074, Volgograd, Russia
}

\begin{abstract}
This article presents the results of a study on the random variability influence of soil deformation parameters - elastic modulus, Poisson's ratio - on the dynamic characteristics of a building. The spatial finite element system "building - pile foundation" is considered, taking into account the reduction in the acceleration of ground vibrations with depth. The probabilistic calculation of the system is carried out by the Monte Carlo method, the random parameters of the subgrade are taken to be distributed according to the normal law. Statistical characteristics of free frequencies of system vibrations were obtained, it was found that within the same soil type, it is possible to realize system vibrations with a predominance of both the 1 st and 2 nd forms.
\end{abstract}

\section{Introduction}

Today, pile foundations are one of the most common types of foundations. The variety of the piles types allows them to be used everywhere, on almost any basis and in various climatic conditions.

However, pile foundations remain extremely labor-intensive in terms of engineering design. Due to its specificity and a large number of different characteristics, it is difficult to unambiguously assess the joint operation of the "building - pile foundation - soil foundation" system.

The analysis of the work of a building on a pile foundation under seismic loads influence raises even more questions for engineers and researchers. According to the Ministry of Emergency Situations, $40 \%$ of the Russian Federation territory is subject to seismic impact with magnitude intensity more than 6 points. In addition, $20 \%$ of the territory where the objects of increased danger are, is located in the zones with magnitude seismicity of 9 or more. These data make the issues of studying the building operation under the seismic loads influence one of the most urgent and acute ones today.

At present, in engineering practice, the so-called classical approach to the "building foundation" system operation analysis is quite widespread. The calculation is carried out in two stages: the base with the load from the overlying building is considered separately and the building itself is separately considered. In addition, when carrying out the calculations,

* Corresponding author: artempride@gmail.com 
it is customary to consider a building rigidly restrained at the base level (like a cantilever bar), which obviously distorts the operation of structures [1]. This issue is discussed in detail in the works $[2,3,4]$. Numerous studies of the destruction nature of the buildings from after earthquakes have established that under the action of a seismic load, a building and its foundation work as a single spatial system, which is characterized by complex bending-torsional deformations caused by uneven distribution of masses in the abovefoundation structure and its rigidity, inhomogeneous stochastic properties of the soil base, spectral characteristics of seismic impact. In recent years, many scientific publications on the peculiarities of the interaction of a structure and a foundation during an earthquake have appeared: a comparative analysis of the response spectra of a system with a flexible and rigid foundation [5], the effect of various types of soil conditions on the seismic design spectrum of buildings of various heights $[6,7,8]$, the influence of the earthquake frequency composition on the contact stresses under the foundation base [7]. A probabilistic approach taking into account the random variability of the soil base characteristics and seismic load to assess the risk of collapse of a steel frame structure located on soils with shear wave velocities above $150 \mathrm{~m} / \mathrm{s}$ is presented in [9]. The issues of economic feasibility of including provisions on the interaction of soil and structure in the design standards are considered in [10].

In all of the above studies, the compliance of the subgrade is taken into account using a system of springs and dampers that simulate the horizontal, vertical and angular displacements of a surface foundation. In this case, a flat model of the "structure-base" system is considered.

As for modeling the joint work of buildings on a pile foundation under the action of seismic loads, this issue remains poorly studied.

This article presents the results of a study of the influence of stochastic properties of the soil foundation on the dynamic characteristics of the "structure-pile foundation" system using a spatial finite element model. The calculations took into account the recommendations and experience of other authors $[1,11,12]$ involved in related research.

\section{Description of the design model}

Modeling and calculation of the "building - pile foundation" system were carried out in the environment SP LIRA SARP. The design scheme (Fig. 1) is assembled taking into account the recommendations [13] and is a two-storey frame structure (simple stack) $10 \mathrm{~m}$ high. The characteristics of the structures are given in Table 1 .

Piles and soil mass are made of volumetric finite elements. The joint work of the pile and the soil massif is presented in the form of the "pile - soil massif" system according to [14]. To a depth at which the soil resistance along the lateral surface of the pile is not taken into account, two-node finite elements of the corresponding stiffness are installed $K_{x, y}$ [15] with the work exclusively in the horizontal direction.

The stiffness of two-node elements is determined by the formula (1).

Table 1. Characteristics of the design scheme elements

\begin{tabular}{|c|c|c|}
\hline Item name & $\begin{array}{c}\text { Geometric } \\
\text { characteristics }\end{array}$ & Physical characteristics \\
\hline $\begin{array}{c}\text { Floor slab } \\
\text { (coverings) }\end{array}$ & $b=200[\mathrm{~mm}]$ & $\begin{array}{c}\text { Reinforced concrete } \\
E=3 \cdot 10^{6},\left[\mathrm{t} / \mathrm{m}^{2}\right]\end{array}$ \\
\hline Slab grillage & $b=300[\mathrm{~mm}]$ & $\begin{array}{c}\text { Reinforced concrete } \\
E=3 \cdot 10^{6},\left[\mathrm{t} / \mathrm{m}^{2}\right]\end{array}$ \\
\hline
\end{tabular}




\begin{tabular}{|c|c|c|}
\hline Columns & $400 \times 400[\mathrm{~mm}[$ & $\begin{array}{c}\text { Reinforced concrete } \\
E=3 \cdot 10^{6},\left[\mathrm{t} / \mathrm{m}^{2}\right]\end{array}$ \\
\hline Piles & $300 \times 300[\mathrm{~mm}] ; L=9$ & $\begin{array}{c}\text { Reinforced concrete } \\
E=3 \cdot 10^{6},\left[\mathrm{t} / \mathrm{m}^{2}\right]\end{array}$ \\
\hline $\begin{array}{c}\text { Soil massif } \\
\text { (loam) }\end{array}$ & $30 \times 20[\mathrm{~m}] ; H=13$ & $\begin{array}{c}\text { Specific adhesion } \\
C=61[\mathrm{kPa}] ; \\
\text { Internal friction } \\
\text { angle } \varphi=17^{\circ}\end{array}$ \\
\hline
\end{tabular}

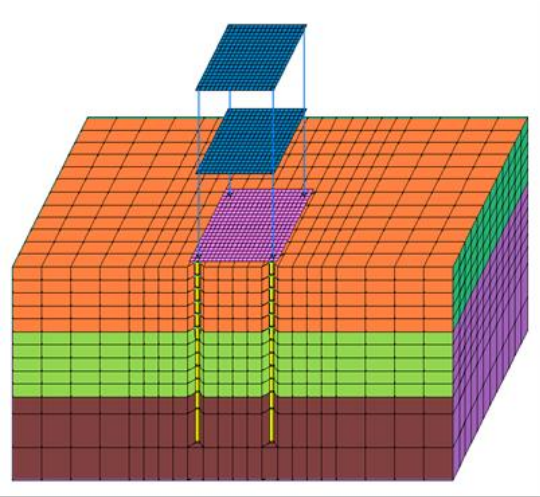

$\mathrm{a}$

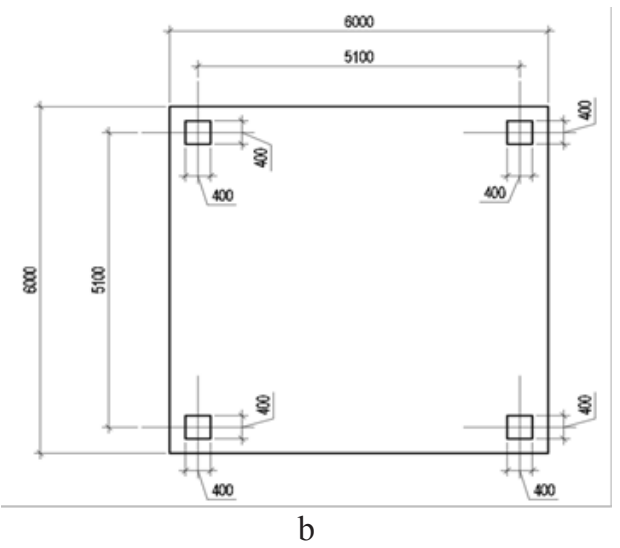

Fig. 1. Calculation scheme: a - volumetric mathematical model; b - construction plan.

$$
K_{x, y}=2 *(1+v) * G * \beta_{x} * \sqrt{A}
$$

$v$ - Poisson's ratio;

$G$-dynamic soil shear modulus;

$\beta_{x}$-pile shape coefficient (with an equilateral pile section is equal to 1 , other cases are presented in [15]);

$A$ - pile cross-sectional area.

The soil is considered as a homogeneous mass, modeled by volumetric finite elements. Random soil parameters - density $\rho$, velocity of propagation of longitudinal $V_{p}$ and transverse $V_{S}$ waves are assumed to be normally distributed. For example, aerated loam soil was selected, the statistical characteristics of which are given in Table 2.

Table 2. The soil parameters' statistical characteristics

\begin{tabular}{|c|c|c|c|c|c|}
\hline \multicolumn{2}{|c|}{ Density $\rho,\left[\mathrm{g} / \mathrm{cm}^{3}\right]$} & \multicolumn{2}{c|}{ Speed $V_{p},[\mathrm{~km} / \mathrm{s}]$} & \multicolumn{2}{c|}{ Speed $V_{s},[\mathrm{~km} / \mathrm{s}]$} \\
\hline $\begin{array}{c}\text { Expected } \\
\text { value }\end{array}$ & Standard & $\begin{array}{c}\text { Expected } \\
\text { value }\end{array}$ & Standard & $\begin{array}{c}\text { Expected } \\
\text { value }\end{array}$ & Standard \\
\hline 1.75 & 0.08 & 0.55 & 0.06 & 0.21 & 0.07 \\
\hline
\end{tabular}

Estimated intensity of seismic impact 7 points.

Correction factor for mathematical expectations of wave velocities $K_{V 7}=0,78$.

To carry out the modal analysis, an equivalent quasi-static design scheme was used, which takes into account a twofold reduction in the acceleration of ground vibrations at a 
depth of 8 meters from the day surface [16]. Equivalent load is determined in accordance with applicable regulations and codes of practice.

\section{Results of numerical simulation}

The soil base characteristics' statistical variability influence assessment on the dynamic characteristics of the model under consideration is carried out by the statistical tests method (Monte Carlo). To get realizations of random variables $\rho_{i}, V_{p i}, V_{s i}$ a random number generator with normal distribution was used. Generation of random variables is performed in the Mathcad environment. Dynamic module implementations, $E_{d i}$, shear modulus $G_{i}$, Poisson's ratio $v_{i}$ and stiffness of nodal elements $K_{x, y}$ were calculated by the formulas (1) (4). We do not take into account the correlation between the random parameters.

$$
\begin{gathered}
E_{d i}=2 \rho_{i} V_{s i}^{2}\left(1+v_{i}\right) \\
G_{i}=\rho_{i} V_{s i}^{2} \\
v_{i}=\left(V_{p i}^{2}-2 V_{s i}^{2}\right) / 2\left(V_{p i}^{2}-V_{s i}^{2}\right)
\end{gathered}
$$

Some simulation results are shown in Table 3 . The speed values are given taking into account their multiplication by the correction factor $K_{V 7}$. For the convenience of calculating and entering the data into the software package SP LIRA the quantities dimensions in Table 3 are written in the converted version.

Table 3. Realization of random soil parameters

\begin{tabular}{|c|c|c|c|c|c|c|c|}
\hline No. & $\begin{array}{c}\text { Density } \\
\rho_{i}, \\
{\left[\mathrm{~kg} / \mathrm{m}^{3}\right]}\end{array}$ & $\begin{array}{c}\text { Speed } \\
V_{p i}, \\
{[\mathrm{~m} / \mathrm{s}]}\end{array}$ & $\begin{array}{c}\text { Speed } \\
V_{s i},[\mathrm{~m} / \mathrm{s}]\end{array}$ & $v_{i}$ & $\begin{array}{c}\text { Elastic } \\
\text { modulus } \\
E_{d i}, \\
{[\mathrm{MPa}]}\end{array}$ & $\begin{array}{c}\text { Shear } \\
\text { modulus } \\
G_{i}, \\
{[\mathrm{MPa}]}\end{array}$ & $\begin{array}{c}\text { Rigidity } \\
K_{x, y}, \\
{[\mathrm{MPa}]}\end{array}$ \\
\hline 1 & 1701 & 392 & 111 & 0.46 & 61 & 21 & 18.4 \\
\hline 2 & 1746 & 388 & 149 & 0.41 & 110 & 38.9 & 33 \\
\hline 3 & 1607 & 494 & 238 & 0.35 & 246 & 91.3 & 73.9 \\
\hline 4 & 1697 & 458 & 171 & 0.42 & 142 & 49.9 & 42.5 \\
\hline \multicolumn{7}{|l|}{} \\
\hline 29 & 1746 & 421 & 243 & 0.25 & 258 & 103.2 & 77.4 \\
\hline 30 & 1777 & 459 & 154 & 0.44 & 121 & 42.3 & 36.4 \\
\hline
\end{tabular}

\section{Analysis of the "building - pile foundation" system dynamic characteristics}

After getting an array of implementations in SP LIRA a cycle of 30 calculations was performed and the impact of the random soil parameters variability on the frequencies and modes of vibration of the system under consideration was assessed (Table 4).

Table 4. Statistical characteristics of the system free oscillations 2 main frequencies

\begin{tabular}{|c|c|c|c|c|}
\hline \multirow{2}{*}{$\begin{array}{c}\text { Statistical } \\
\text { characteristics }\end{array}$} & \multirow{2}{*}{$\begin{array}{c}\text { Elastic } \\
\text { modulus } E_{d}\end{array}$} & \begin{tabular}{c} 
Poisson's \\
ratio, \\
\cline { 3 - 5 }
\end{tabular} & $v$ & \multicolumn{2}{|c|}{ Oscillation frequencies } \\
\cline { 4 - 5 } & $126[\mathrm{MPa}]$ & 0.41 & 20 & 54 \\
\hline Mean & $126 \mathrm{rad} / \mathrm{s}]$ & $\omega_{2},[\mathrm{rad} / \mathrm{s}]$ \\
\hline
\end{tabular}




\begin{tabular}{|c|c|c|c|c|}
\hline Dispersion & $\begin{array}{c}5587.8 \\
{\left[\mathrm{MPa}^{2}\right]}\end{array}$ & 0.005 & 37.52 & 611 \\
\hline Standard & $\begin{array}{c}74.75 \\
{[\mathrm{MPa}]}\end{array}$ & 0.07 & 6.13 & 24.72 \\
\hline $\begin{array}{c}\text { Variation } \\
\text { coefficient }\end{array}$ & 0.6 & 0.17 & 0.3 & 0.46 \\
\hline
\end{tabular}

The calculation results show that the system free vibrations frequencies values have high variability $(30 \%, 46 \%)$ even for one type of soil.

Two predominant modes of vibration of the "building - pile foundation" system with a total modal mass of $99.98 \%$ were established (Fig. 2).

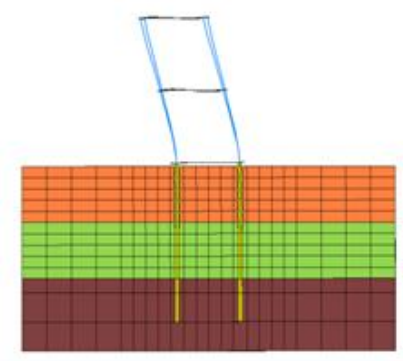

1

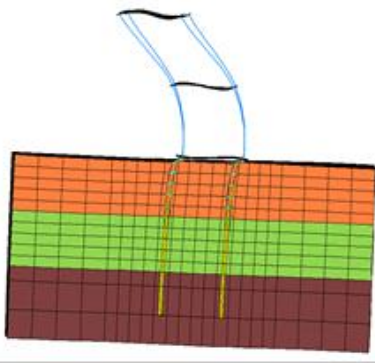

2

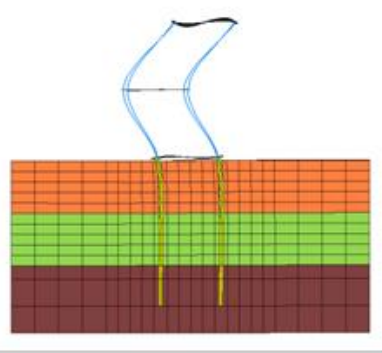

3

Fig. 2. Forms of the structure vibration: 1 - 1st form; 2 - 2nd form; 3rd - 3rd form.

The results obtained, shown in Figure 3, made it possible to reveal some dependences between the modulus of elasticity of the soil and the ratio between the system vibrations frequencies. For greater clarity, the elastic modulus values are arranged in ascending order. The results are presented only for the first two modes of vibrations, since in most cases it is these modes that made an overwhelming contribution to the modal mass.

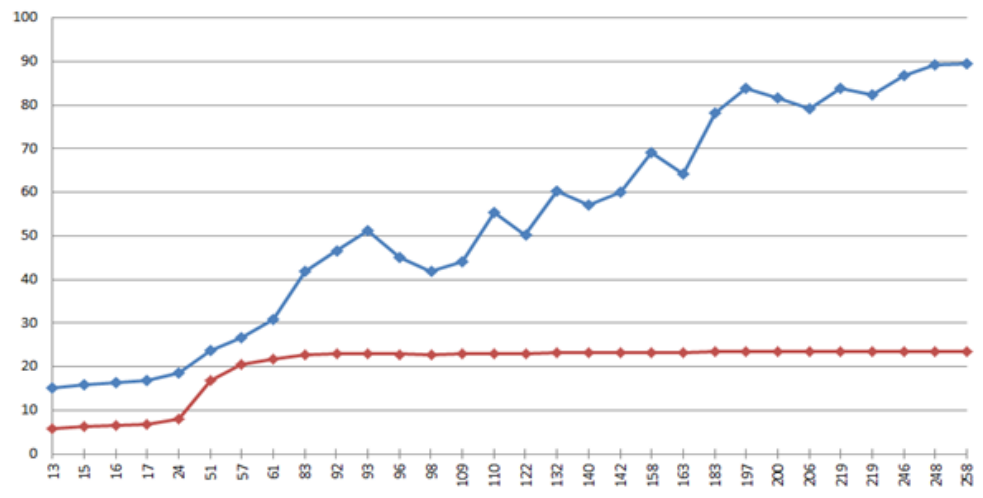

Fig.3. The graph of the structure $\omega$ vibration frequency dependence, $\mathrm{rad} / \mathrm{s}$, from the modulus of elasticity of the soil $E_{d}, \mathrm{MPa}$

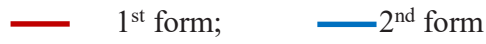

At sufficiently small values of the soil elastic modulus, the predominant contribution to the modal mass is made by the 1st mode of vibration, and with an increase in the value of the elastic modulus, the contribution of the vibration higher modes increases. So, in most cycles of the experiment, the 2nd mode of vibration prevailed, however, in the study of 
cycles with a sharply different modulus of elasticity, a significant contribution was made by the higher modes of vibration, up to the 3rd and 4th (torsional) modes. From this it can be concluded that the modulus of soil elasticity affects not only the frequency, but also the predominant mode of the system vibration. The generalized conclusion on this pattern is presented in Table 5.

Table 5. The system vibration modes interaction nature at different values of the dynamic modulus of elasticity

\begin{tabular}{|c|c|c|}
\hline $\begin{array}{c}\text { Elastic modulus } \\
E_{d i},[\mathrm{MPa}]\end{array}$ & $\begin{array}{c}\text { Contribution of the 2nd } \\
\text { mode of vibration, [\%] }\end{array}$ & $\begin{array}{c}\text { The prevalence of the } \\
\text { 3rd mode of vibration }\end{array}$ \\
\hline$\geq 100$ & $\geq 20$ & - \\
\hline $100 \geq 230$ & $70-90$ & - \\
\hline $230 \geq 260$ & $\approx 20$ & + \\
\hline
\end{tabular}

\section{Conclusion}

The quasi-static model adopted in this work is rather arbitrary, but it allows a qualitative assessment of the "building-pile foundation" system dynamic characteristics variability depending on the deformation properties of the foundation soils.

The high variability of the dynamic modulus of elasticity of the soil $(60 \%)$ leads to a large spread in the values of the "structure-pile foundation" system free vibrations frequencies, which is $30 \%$ and $46 \%$ of the average values for the considered type of soil.

The probabilistic analysis carried out on the aerated loam example shows that within the same type of soil, it is possible to realize system oscillations with a predominance of both the 1 st and 2 nd forms.

The design scheme of a building in the form of a cantilever-pendulum model with a rigid embedment at the base, which is currently used in engineering calculations of structures on pile foundations, does not give an idea of the structure-foundation system free vibration modes interaction nature. The discrepancy in the values of natural frequencies, calculated by two models is $50-80 \%$.

In the future, the authors set the task of studying the work of more complex models of high-rise buildings on a pile foundation.

\section{References}

1. D.M. Nuriyeva, News of KSACU. Bases and foundations, underground structures 4(30), 214-221 (2014).

2. A.G. Tyapin, Taking into account the interaction of structures with the foundation when calculating seismic effects (Scientific publication, ASV Publishing House, 2014).

3. A.M. Uzdin, T.A. Sandovich, Al-Nasser-Muhomad Samih Amin, Fundamentals of the theory of seismic resistance and earthquake-resistant construction of buildings and structures, Publishing house of All-Russian Scientific Research Institute of Hydraulic Engineering named after B.E. Vedeneev, St. Petersburg, 1993.

4. B. Ganjavi, I. Hajirasouliha, A. Bolourchi, Soil Dynamics and Earthquake Engineering 88, 356- 368 (2016).

5. Sagar K. Chhetri, Kamal B. Thapa, Proceedings of IOE Graduate Conference (2015) $75-87$.

6. I. Oz, Sevket M. Senel, M. Palanci, A. Kalkan, Appl. Sci. 10, 8357 (2020). 
7. H. Matinmanesh, M. Saleh Asheghabadi, Procedia Engineering 14, 1737-1743 (2011).

8. R. Singh, V. Oshin, Shilpa I. Jain, A review, AIP Conference Proceedings 2158, 020007 (2019).

9. S. Vaseghiamiri, M. Mahsuli, M.A. Ghannad, F. Zareian, Journal of Structural Engineering 146 (9) (2020).

10. A. Worku, J. S. Afr. Inst. Civ. Eng. Midrand 56 (1) (2014).

11. Ya.M. Eisenberg, S.K. Gaipov, Elastoplastic work of a reinforced concrete pile in the "pile in a pipe" system under seismic influences, Earthquake resistant construction. Safety of structures, Moscow, 2012, Issue. 2.

12. Yu.P. Nazarov, E.V. Poznyak, Bases, foundations and soil mechanics 5, 17-20 (2014).

13. A.S. Gorodetsky, L.G. Batrak, D.A. Gorodetsky, M.V. Liznyuk, S.V. Yusupenko, Calculation and design of structures of high-rise buildings from monolithic reinforced concrete (Fact, Kiev, 2004).

14. V.A. Pshenichkina, A.S. Zhidenko, K.N. Sukhina, K.A. Sukhin, IOP Conf. Series: Materials Science and Engineering 913, 022011 (2020).

15. A.N. Birbrayev, Structural analysis for seismic resistance (Science, SPB., 1998).

16. V.A. Ilyichev, Yu.V. Mongolov, V.M. Shaevich, Pile foundations in seismic areas (Stroyizdat, Moscow, 1983). 